\title{
Latitudinal Distribution, Migration, and Testosterone Levels in Birds
}

\author{
L. Z. Garamszegi, ${ }^{1, *}$ K. Hirschenhauser, ${ }^{2}$ V. Bókony, ${ }^{3}$ M. Eens, ${ }^{1}$ S. Hurtrez-Boussès, ${ }^{4}$ A. P. Møller, ${ }^{5}$ \\ R. F. Oliveira, ${ }^{6}$ and J. C. Wingfield ${ }^{7}$
}

1. Department of Biology, University of Antwerp,

Universiteitsplein 1, B-2610 Wilrijk, Belgium;

2. Konrad Lorenz Forschungsstelle, A-4645 Grunau 11, Vienna, Austria;

3. Department of Limnology, University of Pannonia, Pf. 158, H8201 Veszprém, Hungary;

4. Génétique et Evolution des Maladies Infectieuses, Unité Mixte de Recherche (UMR) Centre National de la Recherche Scientifique (CNRS)-Institut de Recherche pour le Développement 2724, B.P. 64501, 911 Avenue Agropolis, F-34394 Montpellier Cédex 5, France;

5. Laboratoire de Parasitologie Evolutive, CNRS UMR 7103, Université Pierre et Marie Curie, Bâtiment A, 7ème étage, 7 Quai St. Bernard, Case 237, F-75252 Paris Cédex 5, France;

6. Instituto Superior de Psicologia Aplicada, Rua Jardim do Tabaco 34, 1149-041 Lisboa, Portugal;

7. Department of Biology, University of Washington, Seattle, Washington 98195

Submitted July 31, 2007; Accepted April 15, 2008;

Electronically published August 25, 2008

Online enhancement: appendix.

ABstract: Tropical bird species usually have lower testosterone (T) levels during breeding than temperate species. However, the potential mechanisms behind the positive interspecific correlation between $\mathrm{T}$ and latitude remain unexplored. In a comparative study of more than 100 bird species, we examined whether social constraints during male-male competition arising from migration and breeding synchrony are responsible for the latitude effects. Species that breed at higher latitudes are more likely to migrate and experience more intense intrasexual competition upon spring arrival than nonmigrant species from lower latitudes. Additionally, species from higher latitudes cope with shorter breeding seasons and thus with more synchronous breeding, which selects for high $\mathrm{T}$ titers via increased malemale conflicts. Accordingly, peak $\mathrm{T}$ levels were associated with migration and the duration of the egg laying period that reflects

* Corresponding author; e-mail: laszlo.garamszegi@ua.ac.be.

Am. Nat. 2008. Vol. 172, pp. 533-546. () 2008 by The University of Chicago. 0003-0147/2008/17204-42770\$15.00. All rights reserved.

DOI: $10.1086 / 590955$ breeding synchrony. Because migration and breeding synchrony were related to latitudinal distribution, they appear to be important components of the latitude effects on T. A multivariate model controlling for covariation of predictor variables revealed that latitude remained the strongest predictor of peak $\mathrm{T}$. Therefore, selection due to migration and breeding synchrony may partially cause the latitude effect, but other geographically varying factors may also play a role in mediating peak $\mathrm{T}$ levels at different latitudes.

Keywords: aggression, androgens, evolution, phylogeny, steroid hormones, territorial conflicts.

Testosterone ( $\mathrm{T}$ ) is an important steroid hormone that regulates morphological, physiological, and behavioral control of reproduction in males of many vertebrate taxa (Schulkin 1998). Birds are by far the most studied organisms for the neuroendocrine aspects of reproductive behavior in natural contexts, and circulating levels of $\mathrm{T}$ have been suggested to serve as the physiological basis for sexual selection (Ketterson and Nolan 1992; Wingfield and Farner 1993; Garamszegi et al. 2005). Laboratory and field experiments have repeatedly revealed that higher $\mathrm{T}$ levels can enhance mating success via the expression of secondary sexual characters, the intensity of mate guarding or sperm production, and the extension of home ranges and territories (e.g., Silverin 1980; Watson and Parr 1981; Moore 1984; Wingfield 1984a; Hegner and Wingfield 1986; Marler et al. 1988; Schwabl and Kriner 1991; Ketterson et al. 1992; Beletsky et al. 1995; Saino and Møller 1995; Hunt et al. 1997; Raouf et al. 1997). Temporal variation in T levels may be particularly important in male-male competition (Wingfield et al. 1990a). Aggressive behaviors during formation of hierarchies or territory establishment when individuals frequently challenge each other stimulate rapid rises in plasma concentrations of androgens (Wingfield 1984b; Hirschenhauser and Oliveira 2006). Accordingly, seasonal breeding involving intense male-male competition often drives a correlation between high $\mathrm{T}$ levels and periods of social instability, while long-term pair bonds or the lack of territoriality is often associated with lower T levels during breeding (Wingfield et al. 1987). 
Another typical interspecific correlate of $\mathrm{T}$ titers is latitudinal distribution (Hunt et al. 1995), a consistent trend that persists across a variety of New and Old World species of birds (Goymann et al. 2004; Garamszegi et al. 2005). Birds breeding at tropical latitudes usually have low plasma $\mathrm{T}$ levels throughout the breeding season, while temperate birds tend to have elevated levels peaking during a short period (e.g., Levin and Wingfield 1992; Hunt et al. 1995; Wingfield et al. 1997; Hau et al. 2000; Wikelski et al. 2003), although some tropical birds can have levels comparable with those of temperate species (Moore et al. 2002; Goymann et al. 2004). The latitudinal trend is even obvious at the intraspecific level, when the comparison is made between tropical and temperate populations of the same species (Rodl et al. 2004; Goymann et al. 2006).

However, latitudinal distribution per se is not the direct cause of differences in T levels. There may be several important ecological factors that vary from the equator toward the poles (Blackburn and Gaston 1996; Arnold and Owens 1998; Cardillo 2002; Hawkins et al. 2003; Turner 2004), which remain to be carefully examined in association with hormone levels. The latitude effect is usually interpreted as the consequence of differences in the stability of the social environment, with which birds have to cope at a given latitude (Hunt et al. 1995). In the tropics, especially in lowland tropical rainforests, several species live in stable and saturated environments and may breed throughout the year, resulting in a higher tendency of asynchronous nesting and low rates of extrapair paternity (Kunkel 1974; Stutchbury and Morton 2001). On the other hand, species breeding at temperate latitudes frequently have short reproductive seasons that synchronize reproductive attempts and thus enhance competition between males for access to females or territories. Such short and synchronous breeding corresponds to shorter periods of elevated T (Hunt et al. 1995; Wingfield et al. 1997). At the very extremes, penguins with an antarctic distribution typically have very limited time available for breeding, which involves bursts of high $\mathrm{T}$ titers (Groscolas et al. 1986; Chèrel et al. 1994; Mauget et al. 1994; Jouventin and Mauget 1996). Consequently, the most evident candidate for the latitude effect is breeding synchrony that drives intense male-male competition. However, it should be noted that not all tropical species inhabit benign environments. Frequent predation, dry seasons, flooding, and adaptation to high altitudes provide unfavorable situations for breeding, which can result in breeding synchrony and thus competition for territories favoring elevation of $\mathrm{T}$ (Goymann et al. 2004).

Here we propose another mechanism that may also mediate the latitude effect via male-male interactions: $\mathrm{mi}-$ gration. Migration is a phenomenon by which animals avoid harsh conditions during a certain period of the year
(Berthold 2001; Alerstam et al. 2003). Birds show typical migration patterns as they move toward wintering sites at lower latitudes, where they experience favorable conditions to survive outside the breeding season. As wintering conditions become more demanding at higher latitudes, species breeding closer to the poles should be more likely to migrate than species from lower latitudes (Martin and Wiebe 2004). In addition, migration involves intense malemale competition. Males of migrant species have to establish territories very quickly after arrival, because they have to complete the breeding attempt in time to allow preparation for autumn migration (Lozano et al. 1996; Hasselquist 1998; Kissner et al. 2003; Rubolini et al. 2005; Kokko et al. 2006). The need for fast territory establishment implies intense competition for food, space, and mates, all of which select for higher levels of androgen concentrations (Wingfield et al. 1990a). As the importance of strict timing of migration increases toward the poles, steroid hormone concentrations that enable individuals to cope with the increasing frequency of social challenges should be associated with migration. Therefore, if there is a relationship between latitude and migration and between migration and intensity of sexual selection via male-male conflicts, migration can potentially drive a relationship between latitudinal distribution and $\mathrm{T}$ levels.

In this comparative study of 121 avian species, we examine the constraints of breeding synchrony and migration as potential components producing the latitude effect on peak $\mathrm{T}$ levels during breeding. We collected information on $\mathrm{T}$ concentrations from the literature while recording latitudinal distribution and migration behavior for each population sampled. We also collected information on the duration of the egg laying period, which may mirror the degree of breeding synchrony. First, we separately examined the relationship of $\mathrm{T}$ with breeding latitude, migration, and laying period. We predicted that latitude and migration would be positively related and laying period negatively related to T levels. Second, we tested whether migration or breeding synchrony or both are responsible for the latitude effects. Accordingly, we predicted relationships between latitude and these predictor variables. In addition, a statistical model that simultaneously included latitude, migration, and our estimate of breeding synchrony should reveal no effect for latitude if the chosen predictors entirely explained the latitude effect. On the other hand, if there were remaining variance due to latitudinal distribution to be explained, latitude should be a significant predictor of $\mathrm{T}$ when migration and egg laying period were controlled. Finally, we assessed the importance of the potentially confounding effect of mating system and similarity in phenotype among species due to common ancestry. For any pattern to be robust, we predicted the 
relationship with $\mathrm{T}$ levels to be independent of these confounding factors.

Throughout the article, we assumed that species variation in peak $\mathrm{T}$ represents variation in the effectiveness of the hormone. This is important because evolution of endocrine mechanisms may also operate, in theory, via target sensitivity (e.g., the concentration or affinity of steroid hormone receptors; Dufty et al. 2002), with which we cannot deal because of lack of data. However, we can infer that $\mathrm{T}$ titers measured in the blood are subject to selection because they are repeatable within species (Garamszegi et al. 2005), and previous comparative studies provided biologically meaningful correlations with a list of predictor variables (Wingfield et al. 1990a; Hirschenhauser et al. 2003; Goymann et al. 2004; Garamszegi et al. 2005; Ketterson et al. 2005; Møller et al. 2005; Bókony et al. 2008). This would not be the case if the relationship between $T$ and behavior were mediated by target sensitivity and were independent of circulating hormone levels. In any case, we aimed to investigate the latitude effect on $\mathrm{T}$, which is concerned with peak $\mathrm{T}$ levels by definition (Goymann et al. 2004). Moreover, although some previous comparative studies focused on social modulation of $\mathrm{T}$ levels above the breeding baseline (i.e., responsiveness sensu Wingfield et al. 1990a; Hirschenhauser et al. 2003), this article addresses factors that regulate peak hormone levels independent of baseline levels. We focused on peak $\mathrm{T}$ levels, because these levels generally correspond to the physiological levels measured during the prebreeding (mating) period or territorial challenges (Hirschenhauser et al. 2003), which is most relevant for our working hypotheses. In addition, when we aim to understand the latitudinal effect, that is, why tropical birds tend to generally have lower $\mathrm{T}$ levels, we need to use absolute hormone concentrations rather than relative measures of responsiveness (Goymann et al. 2004). A practical benefit of using peak levels is that such information is available for the majority of species sampled, while it is often difficult to extract information on breeding baseline levels in a repeatable way (Garamszegi et al. 2005).

\section{Methods}

\section{Data Set}

We extracted data on circulating levels of mean peak $\mathrm{T}$ $(\mathrm{ng} / \mathrm{mL})$ during breeding from the primary literature as of December 31, 2006, using availability of data as the primary selection criterion. Although previous comparative studies reported summary tables for T levels for many species (Wingfield et al. 1990a; Hirschenhauser et al. 2003; Goymann et al. 2004; Garamszegi et al. 2005; Ketterson et al. 2005; Møller et al. 2005; Bókony et al. 2008), we avoided the mixture of data from these secondary sources because they relied on different data collection methods and criteria. Moreover, information for several additional species became available in recent years. We combined data on both passerines and nonpasserines, because any potential differences between these groups are controlled for in a phylogenetic context (see below). However, separate analyses for passerines and nonpasserines revealed patterns similar to those we report below for the combined data (separated results for songbirds and nonsongbirds are given in table Al in the online edition of the American Naturalist).

Studies differ in the intensity of sampling, and some studies were made in captivity while others were field studies. Furthermore, Wingfield et al. (1990a), Goymann et al. (2004), and Fusani et al. (2005) suggested that differences in procedures among laboratories may increase noise in the data. All studies, except one that relied on enzymelinked immunosorbent assay, (Deviche et al. 2006), used radioimmunoassay procedures. Results from Goymann's lab indicated that the use of two different antibodies in radioimmunoassay yielded the same $\mathrm{T}$ concentrations (Goymann et al. 2006), so we assumed that differences across studies due to differences in the antibodies used caused only a minor error, if any. Wherever it was possible, we used information on $\mathrm{T}$ levels that were separated from 5 - $\alpha$-dihydrotestosterone levels. We could not assess the potential problem caused by inseparable hormone levels, since cross-reactivity of antibodies was reported in too few cases to interpret statistically. However, we presume that errors due to methodological differences can be neglected when the aim is to compare species, because multiple data for the same species originating from different sources potentially corresponding to different assay conditions revealed that intraspecific variation is lower than interspecific variation $(F=3.439$, $\mathrm{df}=27,38, P<.001)$. We also verified that more sensitive assays did not produce systematically higher $\mathrm{T}$ measures, and we found that the minimum of concentrations that are still detectable in the blood was unrelated to the measured peak $\mathrm{T}$ (assay sensitivity in $\mathrm{ng} / \mathrm{mL}, r=-0.128, N=43, P=.414)$. Moreover, we excluded data on captive populations and used hormone levels from free-living animals only. In any case, any heterogeneity in the data should produce random noise and not systematic bias, because T levels were measured irrespective of the predictions of this study. In other words, technical differences, if any, should be expected to cause null results and not biologically meaningful correlations. Note that this rationale is inherently applied in previous comparative studies. Consequently, we considered that species-specific values are biologically meaningful in the current interspecific context, and we thus used $\log _{10^{-}}$ transformed peak $\mathrm{T}$ levels for the comparative analyses.

Theoretically, methodological differences between stud- 
ies raise the importance of standard T estimation. Recently, Gerlach and Ketterson (2004, 2005) and Jawor et al. (2005) introduced a method based on the gonadotropin-releasing hormone challenge to produce short-term $\mathrm{T}$ increases that are similar to those produced naturally in response to social stimuli and that are repeatable in magnitude. An anonymous reviewer suggested that this could be a promising method to apply in a range of species to assess individual and species variation in the capacity of $\mathrm{T}$ to respond to different social and behavioral factors.

In a previous study, we assessed the potentially confounding effect of latitudinal distribution by using the midpoint of northernmost and southernmost limits of geographical range as estimated from distribution maps published in standard ornithological handbooks (Garamszegi et al. 2005). Here, we used more precise information on latitudes as provided in the corresponding source. From each article that we used to extract data on $\mathrm{T}$ levels, we also collected latitudinal coordinates for the study populations. In case it was not reported but the locality of the study was exactly provided, we used a map with a high resolution to obtain the associated latitudinal information. We used absolute values of latitudinal coordinates in our models (disregarding whether latitudes were in the Northern or the Southern Hemisphere).

Unfortunately, the degree of breeding asynchrony-for example, as reflected by the so-called breeding synchrony index, which is the percentage of females fertile on any given day during the breeding season (as defined by Kempenaers 1993) — is unknown for many species (we could locate this information for 10 species in our sample). However, as a surrogate, we used the $\log _{10}$-transformed duration of the egg laying period in terms of the number of months in the breeding season during which nests are found with freshly laid eggs. Standard ornithological handbooks usually report annual cycle diagrams (Cramp and Simmons 1977-1994; Poole et al. 1993-2002), which show the normal season for the occurrence of eggs, with margins for early and late eggs. These diagrams generally correspond to a large geographical area covering a considerable proportion of the species' range (Cramp and Simmons 1977-1994). On these diagrams, by considering both peak and off-peak activities, we quantified the number of months to the nearest 0.25 month reflecting the duration of the egg laying phase. If analogous information was presented in the primary source of $\mathrm{T}$ data, we used this estimate in association with the studied population. We also used other handbooks (Dementiev and Gladkov 1967; MacLean 1988; Fjeldså and Krabbe 1990; Del Hoyo et al. 1992-2007; Higgins and Davies 1996; Grimmett et al. 1998) if we could not locate quantitative data on laying period from the two main handbook sources. We assumed that the duration of this period is negatively related to breeding asynchrony, because if nest initiation attempts are well distributed in time, nests with overlapping timing are rare. We tested this assumption by using published data on the breeding synchrony index (Stutchbury and Morton 1995; Spottiswoode and Møller 2004), for which we estimated the duration of the egg laying period as described above (see table A2 in the online edition of the American Naturalist). We found a significant negative correlation between these traits $(r=-0.550, N=28, P=$ .002 ; breeding synchrony index was arcsine-square root transformed). Breeding synchrony and the duration of the egg laying period may depend on the number of broods produced during a season, as shown by their correlation (synchrony index-number of broods: $r=-0.455, N=$ $28, P=.015$; duration of the egg laying period-number of broods: $r=0.615, N=28, P<.001$; number of broods was $\log _{10}$ transformed). However, partial correlations indicated that the duration of the egg laying period was a better predictor of breeding synchrony than the number of broods (synchrony index-duration of the egg laying period: $r=-0.385, N=28, P=.011$; synchrony indexnumber of broods: $r=-0.177, N=28, P=.255)$. Therefore, these analyses verified that the temporal distribution of egg laying attempts is a reliable measure of breeding asynchrony in our comparative study.

In several cases, it was possible to determine the migration status of the studied population from the source article, since it was clearly stated therein. Otherwise, we relied on the exact geographical coordinates as described above, which were overlaid on the distribution maps of species. By doing so, we could precisely identify whether the studied population belonged to migrant or resident populations. We found four species for which both resident and migratory populations were analyzed. We provide the mean values of peak $\mathrm{T}$ for these species, but we excluded them from the analyses to avoid the effect of unbalanced distribution of data in the statistical models. Migration was used as a categorical variable in the analyses.

Mating system can be associated with both $\mathrm{T}$ profiles and latitudes (Wingfield et al. 1990a; Hirschenhauser et al. 2003; Garamszegi et al. 2005); thus, it should be considered as a potentially confounding factor that may mediate a spurious correlation between the focal variables in a correlative study. To estimate the variance in male social mating success, we used mating system, which is the most important determinant of $\mathrm{T}$ profile. We classified species as being (1) monogamous, (2) regularly polygynous, (3) lekking, (4) cooperatively breeding, (5) polyandrous, or (6) promiscuous. This categorization was made on the basis of descriptions in the original source or by using other sources (Møller 1986, 1991; Davies 1991). Mating system was used as a factor in the statistical models relying on the raw species data. However, it is difficult to handle 
multistate categories in relation to continuous variables in a phylogenetic context (see Purvis and Rambaut 1995). Moreover, sample size varied enormously across mating system categories, with the majority of species falling in the monogamous group. Therefore, to control for mating system in the phylogenetic context, we tested our predictions for monogamous species only, for which the largest sample was available $(N=91)$. Hence, any effect of latitude, breeding synchrony, or migration within this group should act independently of social mating system to the extent that we deal with this latter effect statistically in this study. The entire data set is presented in table A3 in the online edition of the American Naturalist.

\section{Comparative Methods}

We analyzed the predictions posed in the first section of the article using statistical tests controlling for similarity in variables of interest due to common ancestry, using generalized least squares (GLS) models (Pagel 1997, 1999). We used the computer program CONTINUOUS for the analyses (Pagel 1997). The GLS approach controls for similarity due to common descent, allows investigation of correlated evolution between pairs of characters, estimates ancestral states, examines random-walk versus directional change models, assesses the tempo and mode of trait evolution, and also estimates the importance of phylogenetic corrections. The GLS model characterizes evolutionary changes along each branch of a phylogenetic tree through the variance components of traits (Martins and Hansen 1997; Pagel 1997, 1999). Hypotheses are tested with likelihood ratio statistics. This compares the log-likelihood of the model corresponding to a null hypothesis $\left(H_{0}\right)$ with that of the model for an alternative hypothesis $\left(H_{1}\right)$, where the likelihood ratio $=-2 \log _{\mathrm{e}}\left(H_{0} / H_{1}\right)$. The likelihood ratio statistic is asymptotically distributed as a $\chi^{2}$ variate with degrees of freedom equal to the difference in the number of parameters between the two models. Models contain three scaling parameters that can be used to scale branch lengths in the tree $(\kappa)$, scale total (root to tip) path in the tree $(\delta)$, and assess the contribution of phylogeny $(\lambda)$. We first assessed sequentially the contribution of scaling parameters $\kappa$, branch length scaling factor, and $\lambda$, phylogeny scaling factor (recent simulations showed that the estimation of $\delta$, the overall path length scaling factor, is biased [Freckleton et al. 2002], and thus we avoided estimating this parameter). Once an appropriate model with adjusted scaling parameters had been selected, we studied the correlated evolution of traits of interest by comparing the goodness of fit of model $H_{0}$ fitted to the data by allowing only independent evolution with the alternative $H_{1}$ model, which permits correlated evolution of the characters. We present the phylogenetically corrected correlation coeffi- cient between traits and the associated $P$ values as given by corresponding log-likelihood ratio statistics relying on the most appropriate scaling parameters that had been adjusted for the variables at hand. When we controlled for potentially confounding factors, we entered these variables together with the variables of interest in the same model and assessed the significance of the correlated evolution of the traits considered. If we found significant evidence for correlated evolution, we calculated the partial phylogenetic correlation for the relationship in question. CONTINUOUS accepts binary data. If a single binary trait (e.g., migration) is significantly correlated with a quantitative trait (e.g., T), it should be interpreted as the mean value of the quantitative trait for one group of the binary trait being different from the mean of the other group of the binary trait. However, since the approach has been little tested with categorical variables, we also estimated the effect of migration in a phylogenetic context by using an alternative approach based on independent contrasts. We used the Brunch procedure in the program CAIC to identify all independent contrasts for nodes where transitions occurred in the discrete variable. At these nodes, positive contrasts in $\mathrm{T}$ imply that they vary in the same direction as migration. Using a one-sample $t$-test, we tested

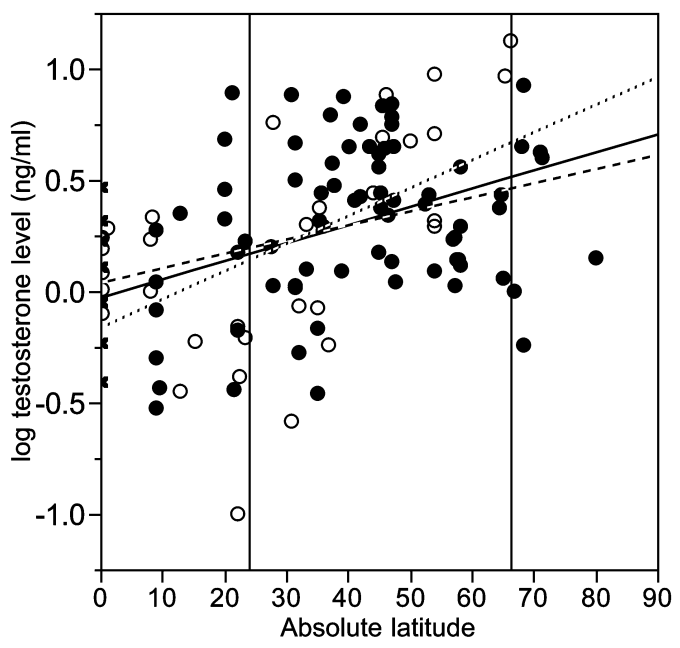

Figure 1: Interspecific relationship between peak testosterone $(\mathrm{T})$ levels $(\mathrm{ng} / \mathrm{mL})$ during breeding and latitudinal distribution. Filled circles are for species from the Northern Hemisphere (latitude $>0$ ), and the corresponding regression line is dashed and has the equation $y=0.04+$ $0.01 x$. Open circles and the dotted regression line represent species from the Southern Hemisphere (latitude $<0$ ), and the corresponding equation is $y=-0.15+0.01 x$. Crosses indicate species from the equator (latitude $=0$ ). The solid line is the linear regression line as calculated from the entire data set, and it has the equation $y=-0.02+0.01 x$. Vertical lines are for the major circles of latitude separating tropical, temperate, and polar zones. The exclusion of the single outlier (lowest T corresponding to Sula sula) does not change the conclusions. 
whether the mean of these contrasts differed from 0 , as expected for correlated evolution of traits. Since the phylogenetic method does not allow insight on phylogenetically transformed data, for illustrative purposes, we present figures based on raw species data.

We constructed a composite phylogenetic hypothesis mainly based on information from Sibley and Ahlquist (1990) derived from extensive studies of DNA-DNA hybridization. This phylogeny for higher taxa was supplemented with additional information from other sources to resolve relationships in taxa with many species (Nunn et al. 1996; Patten and Fugate 1998; Kimball et al. 1999; Searcy et al. 1999; Klicka et al. 2000; Arnaiz-Villena et al. 2001; Sato et al. 2001; Dimcheff et al. 2002; Donne-Goussé et al. 2002; Friesen et al. 2002; Yuri and Mindell 2002; Irestedt et al. 2004; James 2004; Thomas et al. 2004; Klicka et al. 2005; Arbogast et al. 2006; de Kort and Clayton 2006). We applied branch lengths from the tapestry tree of Sibley and Ahlquist (1990) for higher taxonomic levels. Within families, the distance between genera was set to $3.4 \Delta T_{50} H$ units, and the distance between species within genera was set to $1.1 \Delta T_{50} H$ units (see also Sibley and Ahlquist 1990; Bennett and Owens 2002). The composite phylogeny is available from the authors on request.

\section{Results}

\section{Pairwise Correlations}

Using the raw species data, there was a significant positive relationship between latitude and peak $\mathrm{T}$ levels $(r=$ 0.424, $N=117, P<.001$; fig. 1$)$. This latitude effect was most apparent on the tropical-temperate axis, as shown by the comparison of groups with sampling locality within or outside the Tropic of Cancer and the Tropic of Capricorn (means \pm SE; tropical species, $1.438 \pm 0.219$ $\mathrm{ng} / \mathrm{mL}, \quad N=40 ; \quad$ temperate species, $3.276 \pm 0.291$ $\mathrm{ng} / \mathrm{mL}, N=77 ; t=5.329, \mathrm{df}=115, P<.001$; figs. $1-3)$. Focusing on the temperate region, the latitude effect tended to be weakened ( $r=0.181, N=77, P=.113$ ). The relationship between latitude and $\mathrm{T}$ level was similar when the Southern and Northern Hemispheres were considered separately (fig. 1). We controlled for the phylogenetic relationship of species and detected that the latitude effect was not confounded by common ancestry (phylogenetic correlation at $\kappa=0.058, \lambda=0.666: r=$ $0.355, P<.001)$.

We also found a significant relationship between $\mathrm{T}$ and migration, since migrant species had higher titers than resident species ( $t=3.916, \mathrm{df}=116, P<.001$; fig. 2$)$. Notably, average $\mathrm{T}$ level of species, for which reports were available for both migratory and resident species, were intermediate between the means of strictly migratory and resident species (means \pm SE: strictly migrants, $3.853 \pm$ $0.494 \mathrm{ng} / \mathrm{mL}, N=36$; strictly residents, $2.122 \pm 0.209$ $\mathrm{ng} / \mathrm{mL}, N=82$; mixed, $2.154 \pm 0.259 \mathrm{ng} / \mathrm{mL}, N=3$ ). Migration remained a significant predictor of peak $\mathrm{T}$ levels when only temperate samples were considered $(t=$ 2.179 , $\mathrm{df}=77, P=.032$; fig. 2 ). When taking the phylogenetic history of species into account, the relationship between migration and $\mathrm{T}$ levels remained robust (phylogenetic correlation at $\kappa=0.074, \lambda=0.599: r=0.241$, $P=.008$; when using independent contrasts: $t=2.151$, $\mathrm{df}=21, P=.043)$.

The duration of the egg laying period was a significant predictor of peak $\mathrm{T}$. Longer periods reflecting a higher degree of breeding asynchrony were associated with lower hormone levels than were shorter periods $(r=-0.405$, $N=111, P<.001$; fig. 3$)$. That was also the case when only temperate species were considered $(r=-0.344$, $N=79, P=.002$; fig. 3) and in phylogenetic analyses (phylogenetic correlation at $\kappa=0.138, \lambda=0.650: r=$ $-0.278, P=.003)$.

\section{Multivariate Models}

We aimed to explain the latitude effect by two nonexclusive mechanisms: breeding synchrony, as reflected by the duration of the egg laying period, and migration-enhanced male-male interactions. The partial importance of these

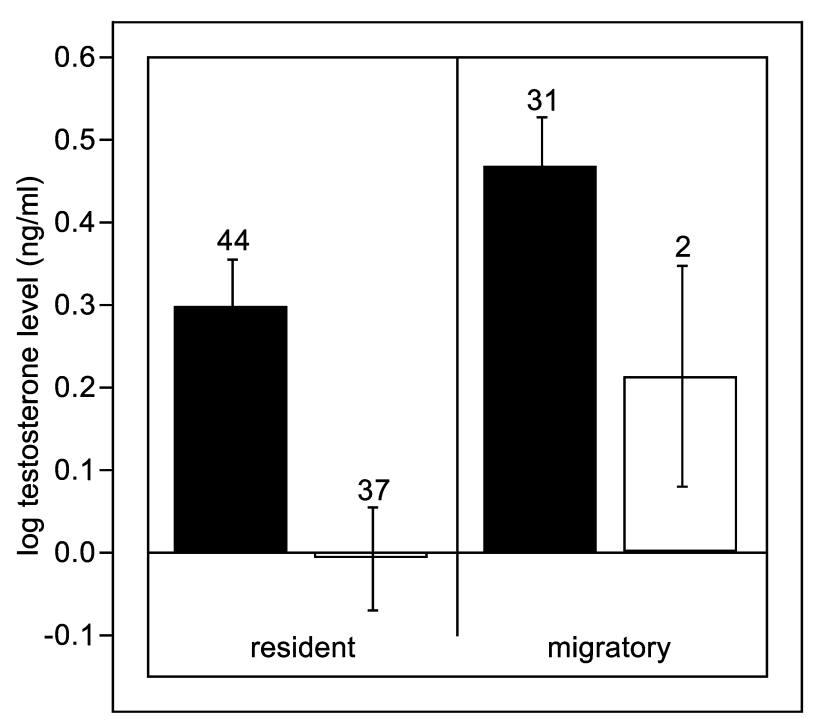

Figure 2: Interspecific relationship between peak testosterone (T) levels during breeding and migratory behavior, as shown by the mean T levels in migrant and resident species when latitudinal distribution is also considered. Filled columns are for temperate species, while open columns represent tropical species. Numbers are sample sizes, and bars are standard errors. 


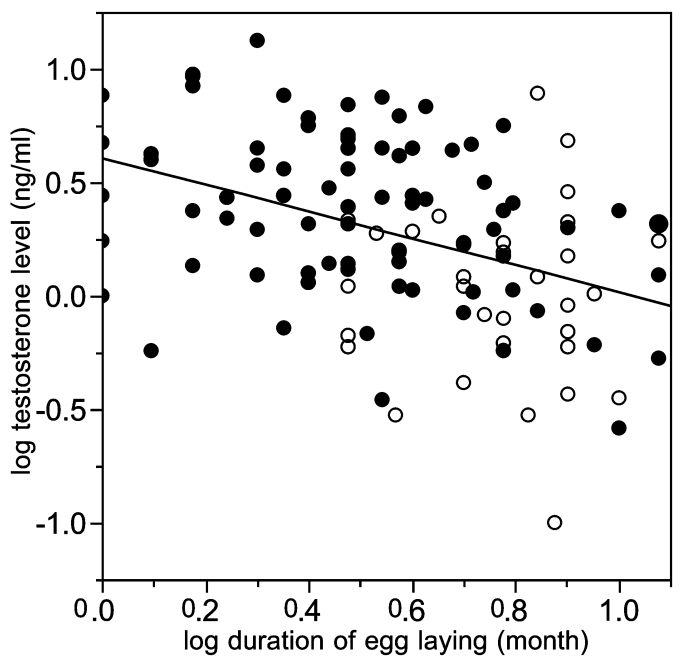

Figure 3: Interspecific relationship between peak testosterone levels (ng/ $\mathrm{mL}$ ) during breeding and duration of the egg laying period (months) that is used to reflect breeding synchrony. Filled and open circles represent temperate and tropical species, respectively. The line is the linear regression line with the equation $y=0.61-0.59 x$.

factors can be assessed in a multivariate model, in which all predictors are used simultaneously. The rationale in that modeling is that if effects due to breeding synchrony and migration mediate the latitudinal trend in $\mathrm{T}$ level, latitudinal distribution should be the strongest predictor because it entirely covers what the other two variables describe. Migration was related to latitudinal distribution, with northern breeders being more likely to migrate (means \pm SE; migrants, $49.314 \pm 2.764, N=33$; residents, $28.153 \pm 2.223, \quad N=81 ; t=5.408, \quad \mathrm{df}=112$, $P<.001$; phylogenetic correlation at $\kappa=0.000, \lambda=$ 0.661: $r=0.393, P<.001$ ), while we also found a strong negative correlation between latitude and duration of the egg laying period (raw species data: $r=-0.564, N=$ 107, $P<.001$; phylogenetic correlation at $\kappa=0.000$, $\lambda=0.654: r=-0.426, P<.001)$. These patterns indicate that the suggested two mechanisms may be responsible for the latitude effect. However, one can also predict that migration or breeding synchrony alone play roles that affect hormone concentrations independent of latitude. For example, tropical species can also migrate and be confronted with unstable social environments that favor high $\mathrm{T}$ levels even at lower latitudes. If such independent effects are of general importance, the multivariate model should reveal that migration or the duration of the egg laying period explain some of the variance in peak $\mathrm{T}$ levels when latitudes are controlled statistically.

When we assessed the partial importance of the three predictor variables in a multivariate model, we found a significant and independent effect for latitude while the predictive power of migration and the duration of the egg laying period decreased, although the corresponding effects remained close to significant (table 1). These findings were confirmed in the analogous phylogenetic model, in which we estimated partial correlations between traits $(\kappa=0.000, \lambda=0.619$, likelihood ratio $=32.295, P<$ .001 for correlated evolution; latitude, $r=0.223, P=$ .024 ; migration, $r=0.154, P=.122$; duration of the egg laying period, $r=-0.118, P=.239$ ).

Finally, we assessed the potentially confounding effect of mating system. We added this variable to the above model, and we arrived at similar conclusions as before (table 1). Reconstruction of the same model taking similarity due to common descent into account revealed similar results $(\kappa=0.000, \lambda=0.530$, likelihood ratio $=$ 29.335, $P<.001$ for correlated evolution; latitude, $r=$ $0.311, P=.006$; migration, $r=0.127, P=.273$; duration of the egg laying period, $r=-0.191, P=.096)$. Therefore, mating system is unlikely to drive the correlations we observed between the traits of interest.

\section{Discussion}

In summary, we found strong statistical evidence for peak $\mathrm{T}$ levels during breeding being a function of spatial distribution at the interspecific and phylogenetic level. Species that bred closer to the poles generally had higher $\mathrm{T}$ levels than species close to the equator. We investigated this lat-

Table 1: Linear models of peak testosterone levels during breeding (dependent variable) and latitudinal distribution, migration, and the duration of the egg laying period reflecting breeding asynchrony (independent variables)

\begin{tabular}{lrcc}
\hline Variable & \multicolumn{1}{l}{ Slope (SE) } & $F$ & $P$ \\
\hline Full model: $^{\mathrm{a}}$ & & & \\
$\quad$ Latitude & $.004(.002)$ & 4.774 & .031 \\
Migration $^{\mathrm{b}}$ & $.076(.044)$ & 3.018 & .085 \\
$\quad$ Egg period & $-.301(.165)$ & 3.313 & .071 \\
Full model: $^{\mathrm{c}}$ & & & \\
$\quad$ Latitude & $.004(.002)$ & 3.392 & .048 \\
$\quad$ Migration & \\
Egg period $^{\mathrm{b}}$ & $.054(.045)$ & 1.418 & .237 \\
Mating system $^{\mathrm{d}}$ & $-.308(.168)$ & 3.363 & .070 \\
\hline
\end{tabular}

Note: Statistics were derived from the raw species data. For phylogenetically equivalent models, see text.

${ }^{a}$ Does not consider mating system as a confounding variable; $F=11.023, \mathrm{df}=3,100, P<.001, r^{2}=.248$.

b Slope for migratory group.

c Considers mating system as a confounding variable; $F=4.990, \mathrm{df}=8,95, P<.001, r^{2}=.296$.

${ }^{d}$ Slope for monogamous group ( $F$ statistics are for the overall effect of mating system). 
itude effect further by examining two candidate components of breeding at different latitudes. First, we showed that migration could cause, at least to some degree, latitudinal variation in hormone profiles, because northern breeders tend to migrate with higher propensity than southern breeders, while migration also had consequences for $\mathrm{T}$ levels. Second, similar patterns were detected for duration of the egg laying period, which was negatively related to both breeding latitude and peak $\mathrm{T}$ concentrations. Multivariate modeling showed that the interspecific differences in migration status and in the duration of the egg laying period seem to be partially responsible for the latitude effect, but a certain amount of latitudinal variance in $\mathrm{T}$ level remains independent of these factors. The conclusions from our analyses were largely independent of latitudinal variation in mating system.

\section{The Effect of Migration}

The findings in association with migration are in accordance with our predictions. In most species of migrants, males compete intensely for early arrival to the breeding grounds because of the fitness advantages accruing to males with early arrival (Lozano et al. 1996; Hasselquist 1998; Kissner et al. 2003; Rubolini et al. 2005; Kokko et al. 2006). Immediately upon arrival, males start displaying, singing, and competing for mates, making it advantageous to raise levels of androgens during the late stages of spring migration. The link between migration and T profile can be clearly seen in the song sparrow Melospiza melodia (Wingfield and Hahn 1994). In North America, western populations are resident and show a peak of $\mathrm{T}$ at the onset of breeding, while eastern populations are short-distance migrants showing a peak on arrival (when gonads are still small) and then a second peak at the onset of breeding. Eastern song sparrows thus have a period of male-male competition for territories upon arrival, which is likely enforced by migration, and then later when females become receptive. If similar roles of migration can be applied to the majority of birds, and selection arising from intense territorial disputes and sexual displays in migrant species may result in adaptive reproductive physiology (Raess and Gwinner 2005), it should be manifested in the observed interspecific relationship with peak T. However, correlations cannot be used to infer causality, and it is important to consider other mechanisms that may shape a relationship between migration and peak $\mathrm{T}$.

Endocrine adaptations to migration have been reported for several hormones (Wingfield et al. 1990b; Wingfield and Silverin 2002; Holberton and Dufty 2005). These hormonal adaptations relate to the different parts of migration, and our working hypothesis particularly corresponds to the transition between migration and breeding. Yet some of them may be associated with the preparation period and others with physiological adaptation to the intense flight, and higher T titers may be part of these processes. For example, certain levels of $\mathrm{T}$ may be required before migration, since without $\mathrm{T}$, birds do not fatten to prepare for elaborate migratory behavior (Wingfield et al. $1990 b$ ). Moreover, the physiological role of T in migratory activity may be manifested via its enhanced effect on locomotory activity, as shown in two experiments using hormone implants (Wada 1986; Ketterson and Nolan 1992). If hormones directly control migration or the premigratory period, we could speculate that $\mathrm{T}$ levels before or during migration would determine the phenology of migration. Given that $\mathrm{T}$ levels outside the breeding season predict hormone profiles during breeding (Garamszegi et al. 2005), it may turn out that our results are just secondary consequences of the direct physiological adaptation occurring before breeding. To examine this possibility, we would need to test for a relationship between migration and $\mathrm{T}$ levels measured in the most relevant period of the year. Unfortunately, such levels are generally unavailable during migration. However, the lowest levels outside breeding (level A sensu Wingfield et al. 1990a), which are measured somewhere between breeding and migration, were not significantly related to migration, when the effect of peak levels was held constant (Wald $\chi^{2}=0.57, N=$ $81, P=.45)$. Therefore, hormonal adaptation to migration by direct control of locomotion through high levels of $\mathrm{T}$ is unlikely. A recent study in garden warblers Sylvia borin has shown that $\mathrm{T}$ increases during migration (Bauchinger et al. 2007). Therefore, selection acting at the breeding grounds via vernal activation of the hypothalamicpituitary-gonad axis is more likely to shape $\mathrm{T}$ profiles in migrant species than factors acting during migration ( $\mathrm{Ra}$ menofsky and Wingfield 2006).

In theory, immunocompetence mechanisms may also mediate a relationship between migration and T. Migration has been proposed to cause considerable costs in terms of increased parasitism (Møller and Erritzøe 1998; Zeller and Murgue 2001; Hubálek 2004; Tracey et al. 2004; Brown et al. 2006), while the efficiency of the immune system may be affected by circulating steroid hormone levels (Folstad and Karter 1992). However, this evolutionary scenario would predict $\mathrm{T}$ levels to be regressed in migratory species as a result of the associated increased costs of parasitism, which was the opposite of what we found.

\section{The Effect of Breeding Synchrony}

The relationship between $\mathrm{T}$ and the duration of the egg laying period corroborates our predictions as well, although it can also be interpreted in different ways. We used the duration of the breeding period to reflect breeding 
synchrony, as supported by available data. Longer egg laying periods can involve, most importantly, temporally distributed breeding attempts but also subsequent opportunities for multiple breeding (Kunkel 1974; Stutchbury and Morton 2001). In contrast, when nesting attempts are temporally concentrated, breeding is relatively synchronous within a population, causing a greater pressure on territory defense and mate acquisition and thereby favoring frequently elevated T levels. Constraints on timing of breeding are more pronounced toward the poles, where shorter periods are available for reproduction (e.g., Eeva et al. 2000; Benson and Winker 2001; Hemborg et al. 2001). Increasing breeding synchrony with increasing latitude should require higher $\mathrm{T}$ levels to cope with intense intrasexual conflicts. Hence, higher $\mathrm{T}$ levels may allow species to achieve high and quick mating success during shorter breeding seasons. Accordingly, species with extended egg laying and low $\mathrm{T}$ levels were more likely to be found in tropical than in temperate regions (fig. 2).

Alternatively, high $\mathrm{T}$ titers in species with short breeding seasons may be a consequence of the costs of $\mathrm{T}$ rather than an adaptation to the intensity of sexual selection. The maintenance of high concentrations of $\mathrm{T}$ is costly, since it involves high risk of injury, immunosuppression, or negative effects on sperm production (Folstad and Karter 1992; Beletsky et al. 1995; Folstad and Skarstein 1997; Hillgarth et al. 1997). Such costs are important to consider, because $\mathrm{T}$ has pleiotropic effects on the expression of a constellation of male traits, such as male reproductive behavior, male secondary sexual characters, and spermatogenesis (Ketterson et al. 2005). Therefore, if selection for one T-dependent trait acts on circulating levels of $\mathrm{T}$, other T-dependent traits will also be coselected, and thus the potential for deleterious side effects will increase. However, such negative effects can be avoided if selection acts on target tissues (via receptor expression for example) instead of plasma levels (Hau 2007) or if individuals express costly levels during a short time (Wingfield et al. 1997). The relationship between costs and benefits associated with an androgenic selection regime could then vary depending on selection acting on both temporal distribution of $\mathrm{T}$ levels and sensitivity of target tissues. Accordingly, in unstable environments (e.g., short breeding seasons), the rapid responses of circulating androgen levels may be favored, and $\mathrm{T}$ may reach high titers that are tolerable during rapid bursts. Conversely, in stable environments (e.g., long breeding seasons), selection may act on the responsiveness of target tissues to T levels, which may allow the endocrine control of male reproductive behavior during a long time period but at a lower T level, which is less costly.

\section{The Reconstruction of the Latitude Effects}

When phylogeny was controlled for, breeding latitudes predicted $\sim 13 \%$ of the interspecific variation in peak $\mathrm{T}$ levels. This is a phenomenon that requires biological explanation, since latitudinal distributions are not the direct causes of the observed hormone levels, and the driving ecological factors need to be identified. We investigated whether the observed latitudinal trend may have resulted, at least partially, from mechanisms in association with migration and breeding synchrony. Migration on its own had a predictive power of $\sim 6 \%$, while the duration of the laying period separately explained $\sim 8 \%$ of the variance. When we entered these predictor variables in a multivariate phylogenetic model together with latitudinal distribution, their effect was weakened. This indicates that components of the latitude effect, to some extent, overlap with components of migration and breeding synchrony. This is in accordance with the hypothesis that mechanisms due to migration and breeding synchrony are responsible for the latitude effect. However, we cannot entirely exclude that migration and the duration of the laying period explain additional variance independent of latitude. When latitudinal distribution was controlled, these factors still contributed, with effect sizes ( $r$ as defined by Cohen 1988) that may be evolutionary relevant $(r>0.1$ sensu Møller and Jennions 2002) corresponding to $2 \%-5 \%$ of the variance in peak T. Some tropical birds possess high hormone titers (Goymann et al. 2004), and not all of them uniformly breed in socially stable and saturated environments. Equatorial species may also migrate and can have short breeding seasons due to various environmental constraints enhancing male-male competition and thus elevating hormone levels similar to the situation in temperate zones (figs. 2, 3; Goymann et al. 2004).

In any case, we found evidence that the latitude effect may partially arise from the intensity of sexual selection in migrant species that are more frequent in the north and from the duration of the available period for breeding that mediates rates of asynchrony or tolerated hormone levels, which are also functions of latitudinal distribution. However, even after eliminating these components, latitude itself remained an important predictor of peak T. Therefore, even though migration and duration of the egg laying period were involved, there remains additional variance that warrants further explanation and investigation of the latitude effect. We can propose at least four potential biological mechanisms and also suggest a statistical issue to consider.

First, levels of parasitism may be dependent on latitudinal distribution since tropical species are likely to host more parasites (Poulin 1995; Møller 1998; Stutchbury and Morton 2001), which may have consequences for circu- 
lating levels of $\mathrm{T}$ as a result of its immunosuppressive side effects (Folstad and Karter 1992). Assuming that species breeding at higher elevations experience less contact with parasites, Goymann et al. (2004) tested this possibility by investigating the relationship between altitudinal distribution and $\mathrm{T}$ levels in tropical species. Although their analysis revealed significant effects when using speciesspecific data, the control for phylogenetic relationships weakened the role of altitude (Goymann et al. 2004). Second, stress levels caused by the unpredictable physical environment may be more prominent at higher latitudes and altitudes because of changing weather conditions. This in turn may influence hormonal adaptations by corticosterone levels (Wingfield et al. 1995; Silverin et al. 1997; Cockrem and Silverin 2002; Wada et al. 2006), with secondary effects on T levels. Third, predator pressure may change with latitudes, which may have consequences for circulating $\mathrm{T}$ levels. Loss of a nest to a predator often results in renesting and further male-male interactions with a receptive female present, again causing further asynchrony of breeding. Although tropical birds may appear to experience generally high predation rates (Skutch 1949; Slagsvold 1982), that is not always the case (Martin et al. 2000). Moreover, we need to explain latitudinal variation in $\mathrm{T}$ levels independent of breeding synchrony, since we have already controlled, at least partially, for such effects in our analyses. However, latitudinally varying predation rates may be worth considering, since they may affect $\mathrm{T}$ levels independent of breeding synchrony. For example, predation may be a selective factor acting via sexual characters that can be controlled by T (e.g., Marler et al. 1988; Schwabl and Kriner 1991; Saino and Møller 1995; Hunt et al. 1997), because such traits are attractive to predators (e.g., Götmark and Post 1996; Møller et al. 2006) and show latitude-dependent expression (Norris et al. 2007). Fourth, some tropical birds may not require high $\mathrm{T}$ levels to mediate reproductive behavior, because they are more sensitive to low hormone levels (Hau et al. 2000; Canoine et al. 2007). Finally, errors in our measurements may contribute to the low explanatory power of migration and laying period. We used these variables to reflect the degree of territorial conflicts through early arrival and breeding synchrony, because these latter variables were unavailable for the majority of the species. Hence, we expect that direct and precise measures of the variables that are the most relevant for the mechanisms at hand would reveal stronger effects.

To conclude, by using birds from all over the world and by controlling for their phylogenetic associations, we have demonstrated a strong relationship between latitudinal distribution and peak T levels during breeding. Further analyses with estimates of migration and breeding synchrony suggested that these factors could partially increase vari- ations in circulating levels of $\mathrm{T}$ during breeding, and they are essential covariates mediating the latitude effect. The findings, in general, are consistent with the hypothesis that the latitudinal effect is mediated by selection due to malemale competition for territories or access to females. However, we could not fully explain the latitude effect. When migration and breeding synchrony were held constant, there was a significant amount of variance in peak $\mathrm{T}$ that remained associated with geographical distribution. Hence, to understand latitudinal gradients in $\mathrm{T}$ levels, other geographically varying factors should be considered in future studies. This is important because differences in the stability of the social environment between the tropics and temperate regions do not necessarily play an exclusive role in governing the latitude effect on $\mathrm{T}$, as traditionally suggested.

\section{Acknowledgments}

We are very grateful to W. Goymann and two anonymous reviewers, who provided constructive comments. L.Z.G. received a postdoctoral grant from the Fonds Wetenschappelijk Onderzoek (FWO)-Flanders. The literature search was partially sponsored by grants from the Fundação para a Ciência e a Technologia (PFCT PRAXIS XXI/BPD/20142/ 99 to K.H. and PRAXIS XXI/P/BIA/10251/98 to R.F.O.). M.E. was funded by various FWO projects. J.C.W. was supported by a grant from the National Science Foundation (IBN-0317141).

\section{Literature Cited}

Alerstam, T., A. Hedenström, and S. Åkesson. 2003. Long-distance migration: evolution and determinants. Oikos 103:247-260.

Arbogast, B. S., S. V. Drovetski, R. L. Curry, P. T. Boag, G. Seutin, P. R. Grant, B. R. Grant, and D. J. Anderson. 2006. The origin and diversification of Galapagos mockingbirds. Evolution 60:370382.

Arnaiz-Villena, A., J. Guillén, V. Ruiz-del-Valle, E. Lowy, J. Zamora, P. Varela, D. Stefani, and L. M. Allende. 2001. Phylogeography of crossbills, bullfinches, grosbeaks, and rosefinches. Cellular and Molecular Life Sciences 58:1159-1166.

Arnold, K. E., and I. P. F. Owens. 1998. Cooperative breeding in birds: a comparative test of the life history hypothesis. Proceedings of the Royal Society B: Biological Sciences 265:739-745.

Bauchinger, U., T. Van't Hof, and H. Biebach. 2007. Testicular development during long-distance spring migration. Hormones and Behavior 51:295-305.

Beletsky, L. D., D. F. Gori, S. Freeman, and J. C. Wingfield. 1995. Testosterone and polygyny in birds. Pages 1-41 in V. Nolan Jr., E. D. Ketterson, and C. F. Thompson, eds. Current ornithology. Plenum, New York.

Bennett, P. M., and I. P. F. Owens. 2002. Evolutionary ecology of birds. Oxford University Press, Oxford.

Benson, A. M., and K. Winker. 2001. Timing of breeding range occupancy among high-latitude passerine migrants. Auk 118:513519. 
Berthold, P. 2001. Bird migration. Oxford University Press, Oxford.

Blackburn, T. M., and K. J. Gaston. 1996. Spatial patterns in the species richness of birds in the New World. Ecography 19:369376.

Bókony, V., L. Z. Garamszegi, K. Hirschenhauser, and A. Liker. 2008. Testosterone and melanin-based black plumage coloration: a comparative study. Behavioral Ecology and Sociobiology 62:1229-1238.

Brown, J. D., D. E. Stallknecht, J. R. Beck, D. L. Suarez, and D. E. Swayne. 2006. Susceptibility of North American ducks and gulls to H5N1 highly pathogenic avian influenza viruses. Emerging Infectious Diseases 12:1663-1670.

Canoine, V., L. Fusani, B. Schlinger, and M. Hau. 2007. Low sex steroids, high steroid receptors: increasing the sensitivity of the nonreproductive brain. Journal of Neurobiology 67:57-67.

Cardillo, M. 2002. The life-history basis of latitudinal diversity gradients: how do species traits vary from the poles to the equator? Journal of Animal Ecology 71:79-87.

Chèrel, Y., R. Mauget, A. Lacroix, and J. Gilles. 1994. Seasonal and fasting-related changes in circulating gonadal steroids and prolactin in king penguins, Aptenodytes patagonicus. Physiological Zoology 67:1154-1173.

Cockrem, J. F., and B. Silverin. 2002. Variation within and between birds in corticosterone responses of great tits (Parus major). General and Comparative Endocrinology 125:197-206.

Cohen, J. 1988. Statistical power analysis for the behavioral sciences. Lawrence Erlbaum, Hillsdale, NJ.

Cramp, S., and K. E. L. Simmons. 1977-1994. The birds of the western Palearctic. Oxford University Press, Oxford.

Davies, N. B. 1991. Mating systems. Pages 263-294 in J. R. Krebs and N. B. Davies, eds. Behavioural ecology: an evolutionary approach. Blackwell Scientific, Oxford.

de Kort, S. R., and N. S. Clayton. 2006. An evolutionary perspective on caching by corvids. Proceedings of the Royal Society B: Biological Sciences 273:417-423.

Del Hoyo, J., A. Elliott, and J. Sargatal. 1992-2007. Handbook of the birds of the world. Lynx, Barcelona.

Dementiev, G. P., and N. A. Gladkov. 1967. Birds of the Soviet Union. Israel Program for Scientific Translations, Jerusalem.

Deviche, P., T. Small, P. Sharp, and K. Tsutsui. 2006. Control of luteinizing hormone and testosterone secretion in a flexibly breeding male passerine, the rufous-winged sparrow, Aimophila carpalis. General and Comparative Endocrinology 149:226-235.

Dimcheff, D. E., S. V. Drovetski, and D. P. Mindell. 2002. Phylogeny of Tetraoninae and other galliform birds using mitochondrial $12 \mathrm{~S}$ and ND2 genes. Molecular Phylogenetics and Evolution 24:203215.

Donne-Goussé, C., V. Laudet, and C. Hänni. 2002. A molecular phylogeny of anseriformes based on mitochondrial DNA analysis. Molecular Phylogenetics and Evolution 23:339-356.

Dufty, A. M., J. Clobert, and A. P. Møller. 2002. Hormones, developmental plasticity and adaptation. Trends in Ecology \& Evolution 17:190-196.

Eeva, T., S. Veistola, and E. Lehikoinen. 2000. Timing of breeding in subarctic passerines in relation to food availability. Canadian Journal of Zoology 78:67-78.

Fjeldså, J., and N. Krabbe. 1990. Birds of the high Andes. Apollo, Stenstrup.

Folstad, I., and A. J. Karter. 1992. Parasites, bright males, and immunocompetence handicap. American Naturalist 139:603-622.
Folstad, I., and F. Skarstein. 1997. Is male germ line control creating avenues for female choice? Behavioral Ecology 8:109-112.

Freckleton, R. P., P. H. Harvey, and M. Pagel. 2002. Phylogenetic analysis and comparative data: a test and review of evidence. American Naturalist 160:712-726.

Friesen, V. L., D. J. Anderson, T. E. Steeves, H. Jones, and E. A. Schreiber. 2002. Molecular support for species status of the Nazca booby (Sula granti). Auk 119:820-826.

Fusani, L., V. Canoine, W. Goymann, M. Wikelski, and M. Hau. 2005. Difficulties and special issues associated with field research in behavioral neuroendocrinology. Hormones and Behavior 48: 484-491.

Garamszegi, L. Z., M. Eens, S. Hurtrez-Boussès, and A. P. Møller. 2005. Testosterone, testes size, and mating success in birds: a comparative study. Hormones and Behavior 47:389-409.

Gerlach, N. M., and E. D. Ketterson. 2004. Behavioral responses to a GnRH challenge in male dark-eyed juncos (Junco hyemalis). Integrative and Comparative Biology 44:699.

2005. Behavioral responses to a GnRH challenge in captive male dark-eyed Juncos (Junco hyemalis). Integrative and Comparative Biology 45:1135.

Götmark, F., and P. Post. 1996. Prey selection by sparrowhawks, Accipiter nisus: relative predation risk for breeding passerine birds in relation to their size, ecology and behaviour. Philosophical Transactions of the Royal Society B: Biological Sciences 351:15591577.

Goymann, W., I. T. Moore, A. Scheuerlein, K. Hirschenhauser, A. Grafen, and J. C. Wingfield. 2004. Testosterone in tropical birds: effects of environmental and social factors. American Naturalist 164:327-334.

Goymann, W., D. Geue, I. Schwabl, H. Flinks, D. Schmidl, H. Schwabl, and E. Gwinner. 2006. Testosterone and corticosterone during the breeding cycle of equatorial and European stonechats (Saxicola torquata axillaris and S. t. rubicola). Hormones and Behavior 50:779-785.

Grimmett, R., C. Inskipp, and T. Inskipp. 1998. Birds of the Indian subcontinent. Helm, London.

Groscolas, R., M. Jallageas, A. Goldsmith, and I. Assenmacher. 1986. The endocrine control of reproduction and molt in male and female emperor (Aptenodytes forsteri) and Adélie (Pygoscelis adeliae) penguins. I. Annual changes in plasma levels of gonadal steroids and LH. General and Comparative Endocrinology 62:43-53.

Hasselquist, D. 1998. Polygyny in great reed warblers: a long-term study of factors contributing to male fitness. Ecology 79:23762390.

Hau, M. 2007. Regulation of male traits by testosterone: implications for the evolution of vertebrate life histories. Bioessays 29:133-144.

Hau, M., M. Wikelski, K. K. Soma, and J. C. Wingfield. 2000. Testosterone and year-round territorial aggression in a tropical bird. General and Comparative Endocrinology 117:20-33.

Hawkins, B. A., E. E. Porter, and J. A. F. Diniz. 2003. Productivity and history as predictors of the latitudinal diversity gradient of terrestrial birds. Ecology 84:1608-1623.

Hegner, R. E., and J. C. Wingfield. 1986. Behavioral and endocrine correlates of multiple brooding in the semi-colonial house sparrow Passer domesticus. I. Males. Hormones and Behavior 20:294-312.

Hemborg, C., J. J. Sanz, and A. Lundberg. 2001. Effects of latitude on the trade-off between reproduction and moult: a long-term study with pied flycatcher. Oecologia (Berlin) 129:206-212.

Higgins, P. J., and S. J. J. F. Davies. 1996. Handbook of Australian, 
New Zealand and Antarctic birds. Oxford University Press, Melbourne.

Hillgarth, N., M. Ramenofsky, and J. C. Wingfield. 1997. Testosterone and sexual selection. Behavioral Ecology 8:108-109.

Hirschenhauser, K., and R. F. Oliveira. 2006. Social modulation of androgens in male vertebrates: meta-analyses of the challenge hypothesis. Animal Behaviour 71:265-277.

Hirschenhauser, K., H. Winkler, and R. F. Oliveira. 2003. Comparative analysis of male androgen responsiveness to social environment in birds: the effects of mating system and paternal incubation. Hormones and Behavior 43:508-519.

Holberton, R. L., and A. M. Dufty Jr. 2005. Hormone patterns and variation in life history strategies of migratory and non-migratory birds. Pages 290-302 in P. Marra and R. Goldberg, eds. Birds of two worlds: the ecology and evolution of migratory birds. Johns Hopkins Press, Baltimore.

Hubálek, Z. 2004. An annotated checklist of pathogenic microorganisms associated with migratory birds. Journal of Wildlife Diseases 40:639-659.

Hunt, K. E., J. C. Wingfield, L. B. Astheimer, W. A. Buttemer, and T. P. Hahn. 1995. Temporal patterns of territorial behavior and circulating testosterone in the Lapland longspur and other arctic passerines. American Zoologist 35:274-284.

Hunt, K. E., T. P. Hahn, and J. C. Wingfield. 1997. Testosterone implants increase song but not aggression in male Lapland longspurs. Animal Behaviour 54:1177-1192.

Irestedt, M., J. Fjeldsa, J. A. A. Nylander, and P. G. P. Ericson. 2004. Phylogenetic relationships of typical antbirds (Thamnophilidae) and test of incongruence based on Bayes factors. BMC Evolutionary Biology 4:23.

James, H. F. 2004. The osteology and phylogeny of the Hawaiian finch radiation (Fringillidae: Drepanidini), including extinct taxa. Zoological Journal of the Linnean Society 141:207-255.

Jawor, J., E. Ketterson, J. Casto, J. McGlothlin, E. Snajdr, T. Greives, G. Bentley, et al. 2005. Seasonal and individual variation in testosterone response to GNRH in free-living male dark-eyed juncos. Hormones and Behavior 48:107.

Jouventin, P., and R. Mauget. 1996. The endocrine basis of the reproductive cycle in the king penguin (Aptenodytes patagonicus). Journal of Zoology 238:665-678.

Kempenaers, B. 1993. The use of a breeding synchrony index. Ornis Scandinavica 24:84.

Ketterson, E. D., and V. Nolan Jr. 1992. Hormones and life histories: an integrative approach. American Naturalist 140(suppl.):S33-S62.

Ketterson, E. D., V. Nolan Jr., L. Wolf, and C. Ziegenfus. 1992. Testosterone and avian life histories: effects of experimentally elevated testosterone on behavior and correlates of fitness in the dark-eyed junco (Junco hyemalis). American Naturalist 140:980-999.

Ketterson, E. D., V. Nolan Jr., and M. Sandell. 2005. Testosterone in females: mediator of adaptive traits, constraint on sexual dimorphism, or both? American Naturalist 166(suppl.):S85-S98.

Kimball, R. T., E. L. Braun, P. W. Zwartjes, T. M. Crowe, and J. D. Ligon. 1999. A molecular phylogeny of the pheasants and partridges suggests that these lineages are not monophyletic. Molecular Phylogenetics and Evolution 11:38-54.

Kissner, K. J., P. J. Weatherhead, and C. M. Francis. 2003. Sexual size dimorphism and timing of spring migration in birds. Journal of Evolutionary Biology 16:154-162.

Klicka, J., K. P. Johnson, and S. M. Lanyon. 2000. New World nine- primaried oscine relationships: constructing a mitochondrial DNA framework. Auk 117:321-336.

Klicka, J., G. Voelker, and G. M. Spellman. 2005. A molecular phylogenetic analysis of the "true thrushes" (Aves: Turdinae). Molecular Phylogenetics and Evolution 34:486-500.

Kokko, H., T. G. Gunnarsson, L. J. Morrell, and J. A. Gill. 2006. Why do female migratory birds arrive later than males? Journal of Animal Ecology 75:1293-1303.

Kunkel, P. 1974. Mating systems of tropical birds: the effects of weakness or absence of external reproduction-timing factors, with special reference to prolonged pair bonds. Zeitschrift für Tierpsychologie 34:265-307.

Levin, R. N., and J. C. Wingfield. 1992. The hormonal control of territorial aggression in tropical birds. Ornis Scandinavica 23:284291.

Lozano, G. A., S. Perreault, and R. E. Lemon. 1996. Age, arrival date and reproductive success of male American redstarts Setophaga ruticilla. Journal of Avian Biology 27:164-170.

MacLean, G. L. 1988. Roberts' birds of South Africa. New Holland, London.

Marler, P., S. Peters, G. F. Ball, A. M. Dufty Jr., and J. C. Wingfield. 1988. The role of sex steroids in the acquisition and production of birdsong. Nature 336:770-772.

Martin, K., and K. L. Wiebe. 2004. Coping mechanisms of alpine and arctic breeding birds: extreme weather and limitations to reproductive resilience. Integrative and Comparative Biology 44: 177-185.

Martin, T. E., P. R. Martin, C. R. Olson, B. J. Heidinger, and J. J. Fontaine. 2000. Parental care and clutch sizes in North and South American birds. Science 287:1482-1485.

Martins, E. P., and T. F. Hansen. 1997. Phylogenies and the comparative method: a general approach to incorporating phylogenetic information into the analysis of interspecific data. American Naturalist 149:646-667.

Mauget, R., P. Jouventin, A. Lacroix, and S. Ishii. 1994. Plasma LH and steroid hormones in king penguin (Aptenodytes patagonicus) during the onset of the breeding cycle. General and Comparative Endocrinology 93:36-43.

Moore, I. T., N. Perfito, H. Wada, T. S. Sperry, and J. C. Wingfield. 2002. Latitudinal variation in plasma testosterone levels in birds of the genus Zonotrichia. General and Comparative Endocrinology 129:13-19.

Moore, M. C. 1984. Changes in territorial defense produced by changes in circulating levels of testosterone: a possible hormonal basis for mate-guarding behavior in white-crowned sparrows. Behaviour 88:215-226.

Møller, A. P. 1986. Mating system among European passerines: a review. Ibis 128:234-250.

- 1991. Sperm competition, sperm depletion, paternal care, and relative testis size in birds. American Naturalist 137:882-906.

- 1998. Evidence of larger impact of parasites on hosts in the tropics: investment in immune function within and outside the tropics. Oikos 82:265-270.

Møller, A. P., and J. Erritzøe. 1998. Host immune defence and migration in birds. Evolutionary Ecology 12:945-953.

Møller, A. P., and M. D. Jennions. 2002. How much variance can be explained by ecologists and evolutionary biologists? Oecologia (Berlin) 132:492-500.

Møller, A. P., L. Z. Garamszegi, D. Gil, S. Hurtrez-Bousses, and M. Eens. 2005. Correlated evolution of male and female testosterone 
profiles in birds and its consequences. Behavioral Ecology and Sociobiology 58:534-544.

Møller, A. P., J. T. Nielsen, and L. Z. Garamszegi. 2006. Song post exposure, song features and predation risk. Behavioral Ecology 17: $155-163$.

Norris, D. R., P. P. Marra, T. K. Kyser, L. M. Ratcliffe, and R. Montgomerie. 2007. Continent-wide variation in feather colour of a migratory songbird in relation to body condition and moulting locality. Biology Letters 3:16-19.

Nunn, G. B., J. Cooper, P. Jouventin, C. J. R. Robertson, and G. G. Robertson. 1996. Evolutionary relationships among extant albatrosses (Procellariiformes: Diomedeidae) established from complete cytochrome- $b$ gene sequences. Auk 113:784-801.

Pagel, M. 1997. Inferring evolutionary processes from phylogenies. Zoologica Scripta 26:331-348.

1999. Inferring the historical patterns of biological evolution. Nature 401:877-884.

Patten, M. A., and M. Fugate. 1998. Systematic relationships among the emberizid sparrows. Auk 115:412-424.

Poole, A., P. Stettenheim, and F. Gill. 1993-2002. The Birds of North America. Academy of Natural Sciences, Philadelphia; and American Ornithologists' Union, Washington, DC.

Poulin, R. 1995. Phylogeny, ecology, and the richness of parasite communities in vertebrates. Ecological Monographs 65:283-302.

Purvis, A., and A. Rambaut. 1995. Comparative analysis by independent contrasts (CAIC): an Apple Macintosh application for analysing comparative data. Computer Applied Biosciences 11: 247-251.

Raess, M., and E. Gwinner. 2005. Gonadal status upon spring arrival in long-distance and short-distance migrating stonechats (Saxicola torquata). Journal of Ornithology 146:325-331.

Ramenofsky, M., and J. C. Wingfield. 2006. Behavioral and physiological conflicts in migrants: the transition between migration and breeding. Journal of Ornithology 147:135-145.

Raouf, S. A., P. G. Parker, E. D. Ketterson, V. Nolan Jr., and C. Ziegenfus. 1997. Testosterone affects reproductive success by influencing extra-pair fertilizations in male dark-eyed juncos (Aves: Junco hyemalis). Proceedings of the Royal Society B: Biological Sciences 264:1599-1603.

Rodl, T., W. Goymann, I. Schwabl, and E. Gwinner. 2004. Excremental androgen metabolite concentrations and gonad sizes in temperate zone vs. tropical stonechats (Saxicola torquata ssp.). General and Comparative Endocrinology 139:124-130.

Rubolini, D., F. Spina, and N. Saino. 2005. Correlates of timing of spring migration in birds: a comparative study of trans-Saharan migrants. Biological Journal of the Linnean Society 85:199-210.

Saino, N., and A. P. Møller. 1995. Testosterone correlates of mate guarding, singing and aggressive behaviour in male barn swallows, Hirundo rustica. Animal Behaviour 49:465-472.

Sato, A., H. Tichy, C. O'hUigin, P. R. Grant, B. R. Grant, and J. Klein. 2001. On the origin of Darwin's finches. Molecular Biology and Evolution 18:299-311.

Schulkin, J. 1998. The neuroendocrine regulation of behavior. Cambridge University Press, Cambridge.

Schwabl, H., and E. Kriner. 1991. Territorial aggression and song of male European robin (Erithacus rubecula) in autumn and spring: effects of antiandrogen treatment. Hormones and Behavior 25: 180-194.

Searcy, W. A., K. Yasukawa, and S. M. Lanyon. 1999. Evolution of polygyny in the ancestors of red-winged blackbirds. Auk 116:519.

Sibley, C. G., and J. E. Ahlquist. 1990. Phylogeny and classification of birds: a study in molecular evolution. Yale University Press, New Haven, CT.

Silverin, B. 1980. The effects of long-acting testosterone treatment on free-living pied flycatchers, Ficedula hypoleuca, during the breeding period. Animal Behaviour 28:906-912.

Silverin, B., B. Arvidsson, and J. Wingfield. 1997. The adrenocortical responses to stress in breeding willow warblers Phylloscopus trochilus in Sweden: effects of latitude and gender. Functional Ecology 11:376-384.

Skutch, A. F. 1949. Do tropical birds rear as many young as they can nourish? Ibis 91:430-455.

Slagsvold, T. 1982. Clutch size variation in passerine birds: the nest predation hypothesis. Oecologia (Berlin) 54:159-169.

Spottiswoode, C., and A. P. Møller. 2004. Extra-pair paternity, migration and breeding synchrony in birds. Behavioral Ecology 15: 41-57.

Stutchbury, B. J., and E. S. Morton. 1995. The effect of breeding synchrony on extra-pair mating systems in songbirds. Behaviour 132:675-690.

. 2001. Behavioral ecology of tropical birds. Academic Press, London.

Thomas, G. H., M. A. Wills, and T. Székely. 2004. A supertree approach to shorebird phylogeny. BMC Evolutionary Biology 4:2845.

Tracey, J. P., R. Woods, D. Roshier, P. West, and G. R. Saunders. 2004. The role of wild birds in the transmission of avian influenza for Australia: an ecological perspective. Emu 104:109-124.

Turner, J. R. G. 2004. Explaining the global biodiversity gradient: energy, area, history and natural selection. Basic and Applied Ecology 5:435-448.

Wada, H., I. T. Moore, C. W. Breuner, and J. C. Wingfield. 2006. Stress responses in tropical sparrows: comparing tropical and temperate Zonotrichia. Physiological and Biochemical Zoology 79:784792

Wada, M. 1986. Circadian rhythms of testosterone-dependent behaviors, crowing and locomotor activity, in male Japanese quail. Journal of Comparative Physiology 158:17-25.

Watson, A., and R. Parr. 1981. Hormone implants affecting territory size and aggressive and sexual behaviour in red grouse. Ornis Scandinavica 12:55-61.

Wikelski, M., M. Hau, W. D. Robinson, and J. C. Wingfield. 2003. Reproductive seasonality of seven Neotropical passerine species. Condor 105:683-695.

Wingfield, J. C. 1984a. Androgens and mating systems: testosteroneinduced polygyny in normally monogamous species. Auk 101:665671

1984b. Environmental and endocrine control of reproduction in the song sparrow Melospiza melodia. II. Agonistic interactions as environmental information stimulating secretion of testosterone. General and Comparative Endocrinology 56:417-427.

Wingfield, J. C., and D. S. Farner. 1993. Endocrinology of reproduction in wild species. Pages 163-327 in D. S. Farner, J. R. King, and K. C. Parkes, eds. Avian biology. Academic Press, New York.

Wingfield, J. C., and T. P. Hahn. 1994. Testosterone and territorial behaviour in sedentary and migratory sparrows. Animal Behaviour 47:77-89.

Wingfield, J. C., and B. Silverin. 2002. Ecophysiological studies of 
hormone-behavior relations in birds. Pages 587-647 in D. W. Pfaff, A. P. Arnold, A. M. Etgen, S. E. Fahrbach, and R. T. Rubin, eds. Hormones, brain and behavior. Elsevier Science, Amsterdam.

Wingfield, J. C., G. F. Ball, A. M. Dufty, R. E. Hegner, and M. Ramenofsky. 1987. Testosterone and aggression in birds. American Scientist 75:602-608.

Wingfield, J. C., R. E. Hegner, J. A. M. Dufty, and G. F. Ball. $1990 a$. The "challenge hypothesis": theoretical implications for pattern of testosterone secretion, mating systems, and breeding strategies. American Naturalist 136:829-846.

Wingfield, J. C., H. Schwabl, and P. W. J. Mattocks. 1990b. Endocrine mechanisms of migration. Pages 232-256 in E. Gwinner, ed. Bird migration. Springer, Berlin.

Wingfield, J. C., K. M. Oreilly, and L. B. Astheimer. 1995. Modulation of the adrenocortical responses to acute stress in arctic birds: a possible ecological basis. American Zoologist 35:285-294.
Wingfield, J. C., J. Jacobs, and N. Hillgarth. 1997. Ecological constraints and the evolution of hormone-behavior interrelationships. Pages 22-41 in C. S. Carter, I. I. Lederhendler, and B. Kirkpatric, eds. The integrative neurobiology of affiliation. New York Academy of Sciences, New York.

Yuri, T., and D. P. Mindell. 2002. Molecular phylogenetic analysis of Fringillidae, "New World nine-primaried oscines" (Aves: Passeriformes). Molecular Phylogenetics and Evolution 23:229-243.

Zeller, H. G., and B. Murgue. 2001. The role of migrating birds in the West Nile virus epidemiology. Medecine et Maladies Infectieuses 31:168S-174S.

Associate Editor: Elizabeth Adkins-Regan Editor: Michael C. Whitlock 